\title{
Evaluation on the Organic Rankine Cycle Generator Sets Firstly Applied in China's Petrochemical Industry
}

\author{
Chi Shenggang ${ }^{1, ~ *, ~ Z h o u ~ T i a n t i a n ', ~ W a n g ~ F a n g s o n g ~}{ }^{1}$ \\ ${ }^{1}$ Aromatic Hydrocarbon Department, SINOPEC Hainan Petrochemical Co., Ltd., Yangpu, China \\ ${ }^{2}$ School of Petroleum Engineering, Guangdong University of Petrochemical Technology, Maoming, China
}

Email address:

chishg@163.com (Chi Shenggang), 1183119267@qq.com (Zhou Tiantian)

${ }^{*}$ Corresponding author

\section{To cite this article:}

Chi Shenggang, Zhou Tiantian, Wang Fangsong. Evaluation on the Organic Rankine Cycle Generator Sets Firstly Applied in China's Petrochemical Industry. International Journal of Oil, Gas and Coal Engineering. Vol. 6, No. 4, 2018, pp. 67-73. doi: $10.11648 /$ j.ogce.20180604.14

Received: July 2, 2018; Accepted: July 16, 2018; Published: August 14, 2018

\begin{abstract}
The Organic Rankine Cycle (ORC) generator sets operated on the low-temperature waste heat device of an aromatics complex is the first demonstration set in the chinese petrochemical industry. By taking this set as an example, the paper introduced the circulation processes of the heating medium water and the ORC working medium in the low-temperature waste heat device. The author also summarized the process and equipment issues during the operation of the sets: in terms of process, improper design of bypass valves in the flow paths of hot water, control authority of the set is not available in DCS, and unstable generator loads under the influence of ambient temperature, etc.; in the field of equipment, bad equipment maintenance \& repair as well as operability, manufacturing fault of KE710 generator, screw expander vibration, and loud running noise, etc. Exploring and solving the problems found in one cycle of the set operation are beneficial to the operation optimization of the ORC generator sets in the future. Therefore, the author proposed such solutions as redesigning the working medium circulating pump and using the latest and optimized screw expander, which resolved part of the problems as well as improved the reliability, maintainability and operability of the ORC generator sets. Through comparison between the calibration data and the operational data of the generator set under the same heat resources, it was found that the set's operating load became less than its calibration load as the heat exchanger started to scale and the screw expander started to wear.
\end{abstract}

Keywords: China’s Petrochemical Industry, Low-Temperature Waste Heat Reuse, ORC Generator Sets, Evaluation

\section{Introduction}

In the petroleum refining process, immense heat at the top of distillation columns needs to be cooled down through water or air coolers due to operational requirements of the production process. Therefore, a considerable volume of low-temperature hot water or air is discharged, and is inefficiently reused in petroleum refining owing to low temperature. According to statistics, energy consumption in the petrifaction industry accounts for 16 percent of the total industrial energy consumption. Currently, the oil refining industry is faced with oil overcapacity and weak profitability. As a result, reasonable utilization of the low-temperature waste heat produced in the process of oil refining is one of the methods to achieve the goals of energy conservation, emission reduction, as well as green and low-carbon development. In theories and practices three methods are used to reuse the heat discharged at the top of distillation columns in the petroleum refining process: heat exchange between thermal insulation materials and demineralized water is utilized to produce hot water at a certain temperature when the temperature at the tower top is between $80^{\circ} \mathrm{C}$ and $150^{\circ} \mathrm{C}$, and then to generate thermoelectricity through Kalina cycle or ORC technology; a waste heat boiler is used when the temperature at the tower top is between $150^{\circ} \mathrm{C}$ and $200^{\circ} \mathrm{C}$, which produces $0.4 \sim 0.5 \mathrm{MPa}$ low-pressure steam to impel the steam turbine generator unit for electricity ${ }^{[3] .}$ The Organic Rankine Cycle (ORC) generator sets operated on the low-temperature waste heat device of an aromatics complex is the world's first demonstration set in the global petrochemical industry. By taking this set as an example, the 
author investigated the existing problems of the set and proposed corresponding solutions [1-3].

\section{Technical Process and Principle of the Low-Temperature Hot Water Power Generation System in an Aromatics Complex}

\subsection{Source of Low-Temperature Waste Heat}

In an aromatics complex, hot water heat exchangers were installed at related locations on the process pipelines on account of heat sources generated by the materials at the deheptanizer, the product tower and the disproportionation stripper, as well as by the products after disproportionated reactions and the waste heat of condensed water. Therefore, heating medium water at $120^{\circ} \mathrm{C}$ was produced after heat exchanges between the demineralized water and the materials above, and was discharged to the low-temperature hot water power generation system (the Kalina unit and ORC unit) for electricity. In this way, part of the energy was recycled to reduce the energy consumption of the sets. Table 1 shows the output of low-temperature heat load and hot water produced by the product tower, deheptanizer, o-xylene distillation and disproportionation, as well as the theoretical power generation data [4].

Table 1. Design heat load and hot water production.

\begin{tabular}{lll}
\hline Heat source & Low temperature heat load / MW & Hot water production $/\left(\mathbf{t} \cdot \mathbf{C}^{-1}\right)$ \\
\hline PX tower heat & 6.544 & 645 \\
Deheptane tower heat & 6.292 & \\
OX tower heat & 24.689 & 170 \\
Condensate heat & 7.900 & 815 (temperature $\left.120^{\circ} \mathrm{C}\right)$ \\
Total & 45.425 & $4306($ winter $)$ \\
\hline
\end{tabular}

\subsection{Circulation Process of Heating Medium Water}

Hot water is delivered by the hot water circulating pump to the deheptanizer, the product tower, the o-xylene distillation column, the product of the disproportionation reaction, the stripper, and the condensate heat exchanger for hot exchange. It then gathers in the low-temperature hot water generation system. A buffer tank was installed at the suction line of the hot water circulating pump to buffer and stabilize the pressure surge at this place. After heat exchange with the heat-exchange equipment in the low-temperature waste heat system, hot water is then discharged to the suction line of the hot water circulating pump for systemic circulation. The flow of heating medium water is divided into three parts: the first part enters into the ORC generator sets, the second part goes into the standby plate heat exchanger for heat exchange, and the third part moves to the Kalina unit. The circulation flow of hot water in actual operations can be decided based on process requirements. The circulation process of the low-temperature heating medium water is shown in Figure 1.

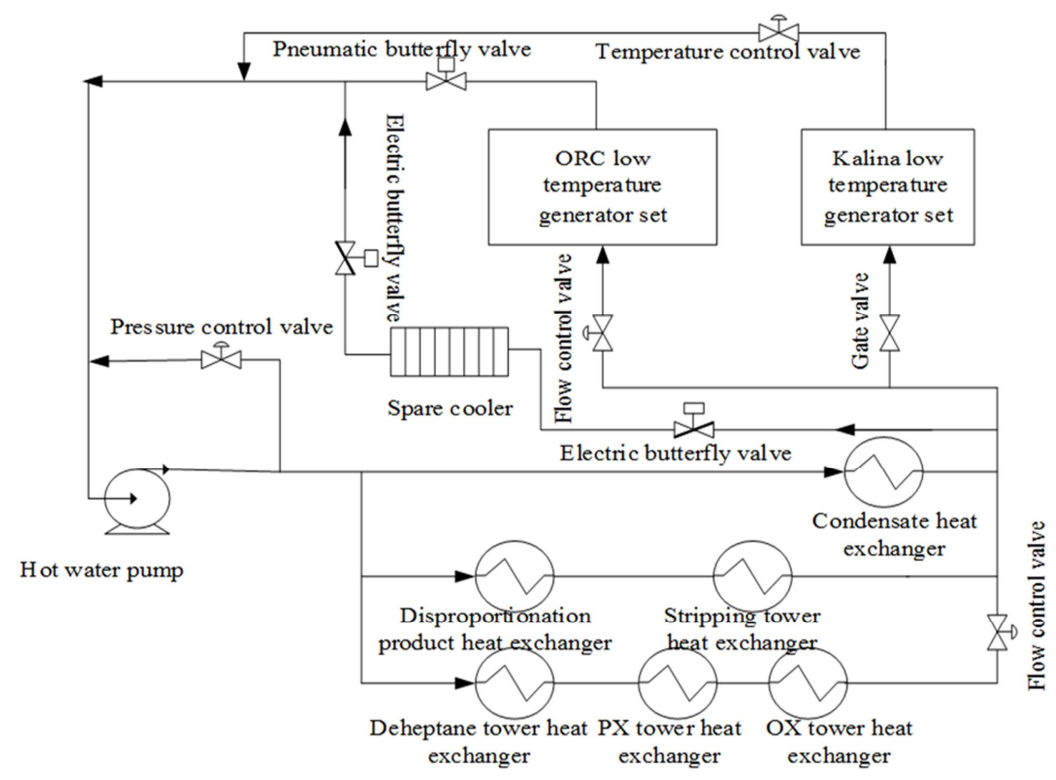

Figure 1. Low temperature heating medium water circulation flow.

\subsection{Hot Water Utilization Flow in ORC}

The ORC generator sets consist of KE710 and KE630, and the working medium circulates individually in a closed cycle and uses cascade control for hot water utilization. After flowing into the KE710 evaporator and exchanging heat with 
the working medium, part of the hot water goes into the preheater to preheat the working in the evaporator; the other part flows into the KE630 evaporator to exchange heat and then into the corresponding preheater to preheat the working medium of the KE630 evaporator; the two parts are then gathered and returned to the hot water network. Flow of hot water in KE710 and KE630 is controlled by the regulating valves at the outlet lines of preheaters. A bypass valve is installed at the outlet line of the KE710 evaporator to regulate the heat load. The cascade control technology has improved the energy utilization efficiency of hot water to some extent. The heating medium water flow in ORC is shown in Figure 2.

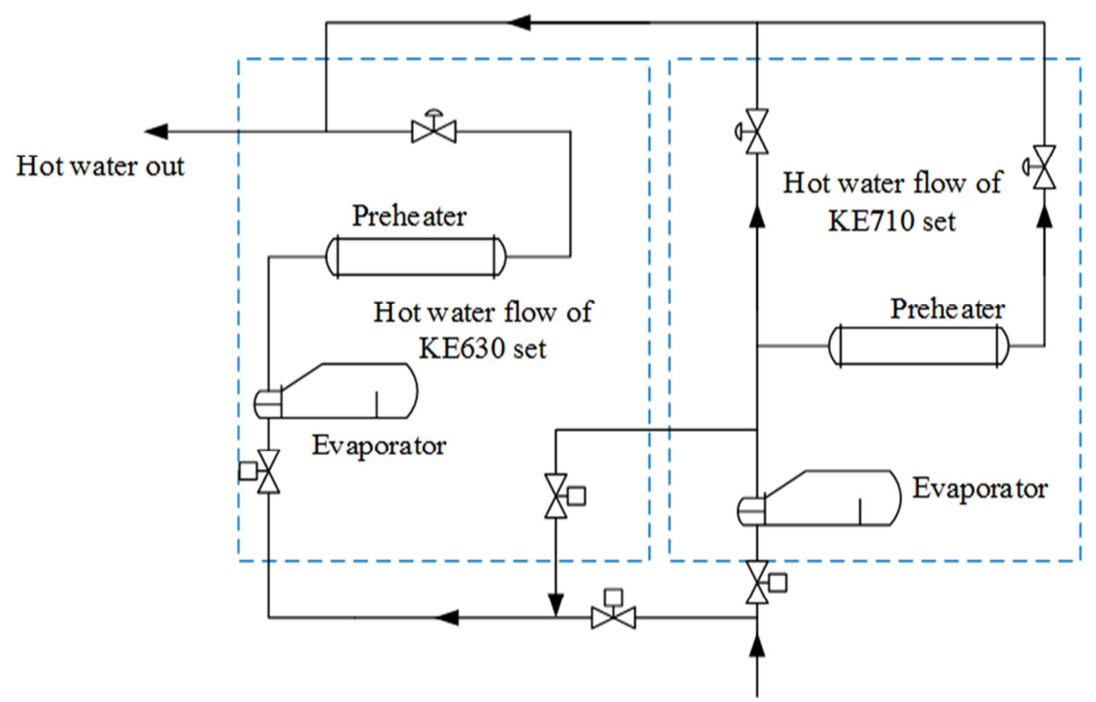

Hot water in

Figure 2. Cascade-control hot water utilization in ORC generator sets.

\subsection{ORC Structure and Working Medium Circulation Flow}

The ORC generator sets are composed of preheater, evaporator, twin-screw expander, asynchronous generator, evaporative condenser, working medium circulating pump, separator, silencer, oil pump, and other equipment, as well as the expander lubrication system, the lubricating oil system for the working medium circulating pump, and some pipelines. Figure 3 demonstrates the principle flow of the working medium. R245fa is the working medium for this low-temperature waste heat generator set, which is powered by the circulating pump in the system [5].

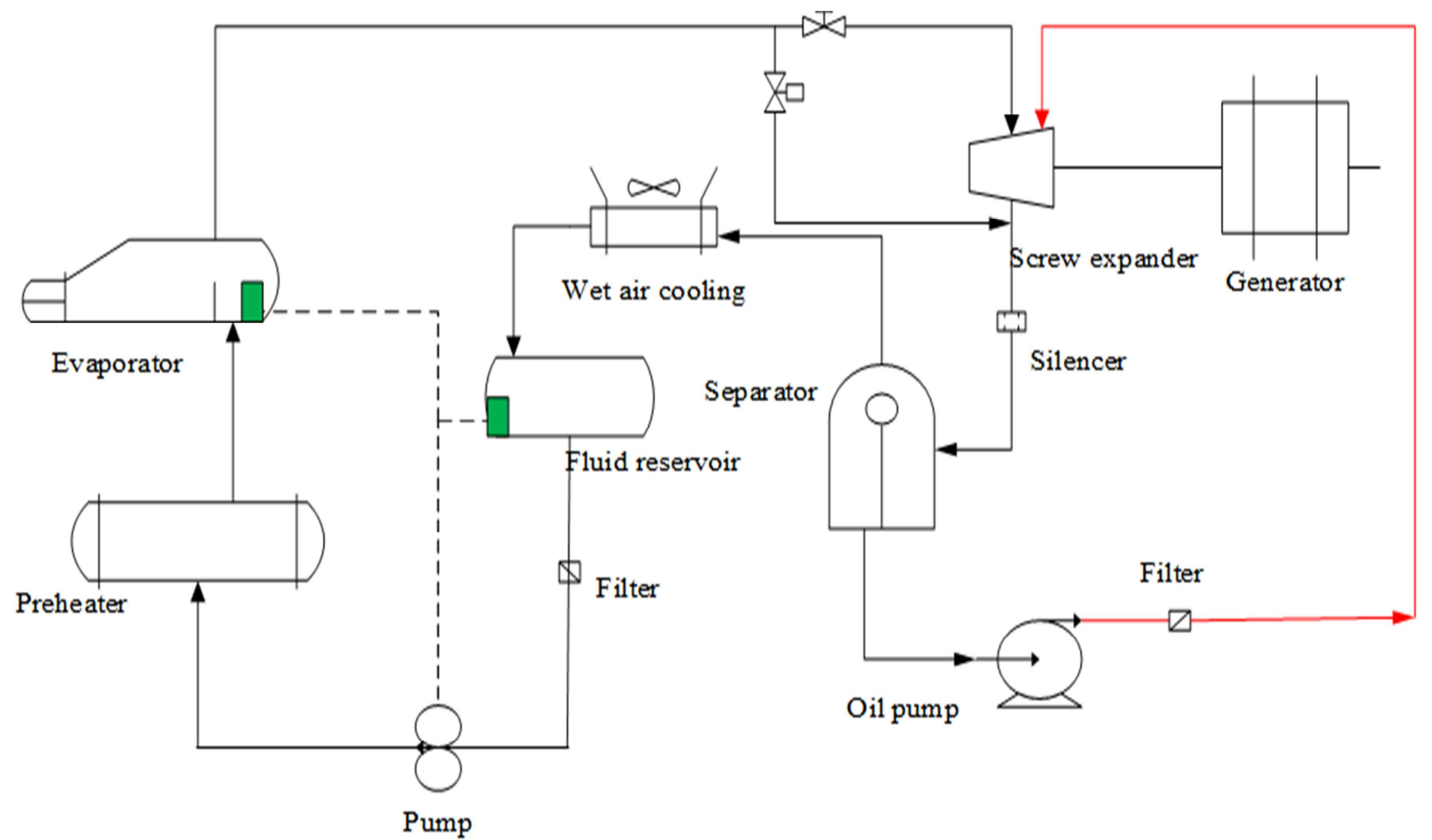

Figure 3. Fluid circulation flow in ORC. 


\subsection{Brief Introduction to the Working Principle of the Core Equipment "Screw Expander"}

The screw expander is a positive displacement rotary design which has the characteristics of both piston and turbine expanders. It is a full-flow power machine and takes the screw compressor as prototype. Molded lines are the basis for the design and development of screw expanders, and its manufacturing process and control system are much more complicated than screw compressors. Screw expanders used in the ORC generator sets for refining adopts the patented screw molded lines with twin-screw 5-6 lobe structure. It consists of male and female rotors, cylinder body, adjusting shim, bearing, bearing kit, and seal assembly, etc. The cylinder body shows the shape of $\infty$ with two intersected and paralleled screw rotors which rotate to the opposite directions according to a certain transmission ratio ${ }^{[6]}$. To reduce leakage of air between the rotors as well as between the rotors and the casing, lubricating oil with a certain amount and pressure is injected in the screw expander during operation, which can cool down and lubricate tooth surfaces and bearings at the same time. The working cycle of the screw expander includes air intake, expansion, and exhaust, and medium pressure varies widely during the whole process. Figure 4 displays the structure diagram of the screw expander, and Figure 5 shows rotor meshing [6-7].

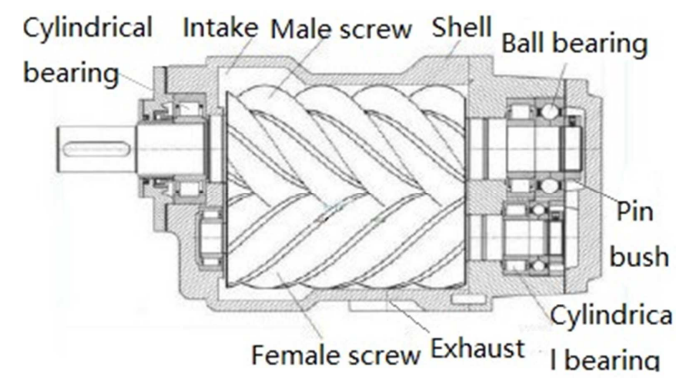

Figure 4. Screw expander structure diagram.

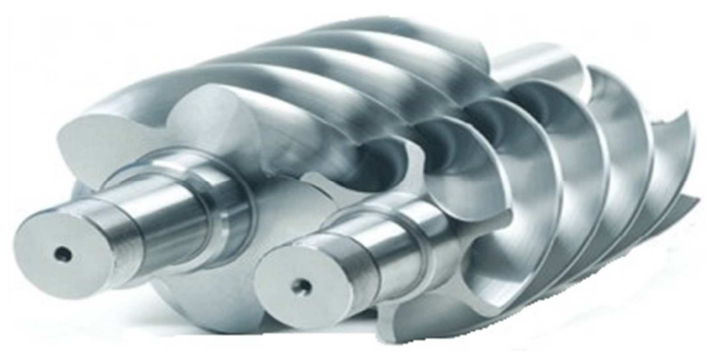

Figure 5. Rotor meshing of the screw expander.

\section{Problems in the Operation of ORC Generator Sets and Relevant Solutions}

\subsection{Problems of the Hot Water Power System Process and Relevant Improvement Measures}

\subsubsection{Unreasonable Control of the Bypass Shutoff Valve in the Hot Water Flow}

Adopting the leading patented hot-water cascade control technology, the ORC generator sets are able to improve power generation efficiency during stable operation; however, KE710 is not stable in practices. When running underload, KE710 can reduce the power generation potential of KE630, leading to low operational efficiency of the whole system. As a system improvement, the bypass shutoff valve can be changed to a flow regulating valve which can independently control the flow of hot water into KE630, thus improving hot water utilization efficiency and changing corresponding control logic [8-9].

\subsubsection{Non-Centralized Control Authority at DCS}

The ORC system adopts S7-300PLC as its host controller to collect data from each measuring point in the system as well as to control and protect the whole unit based on process requirements and control logic. A closed cycle control is adopted in the sets and is completed by the on-site cabinet controller. However, this method is not conducive to process adjustment and optimization as well as system maintenance. Once the evaporator pressure gauge, the condenser pressure gauge, the expander speed gauge or any other gauges with interlocking protection breaks down, DCS is unable to interlock the bypass during maintenance, which will easily cause a false operation shutdown of the system. The DCS panel cannot directly monitor the circulation status of the working medium, the flow of hot water into KE710 and KE630, as well as the temperature of hot water

When the ORC system is under maintenance, it is suggested to integrate the operating authorization of liquid level for evaporators, working medium pump frequency controller, liquid level for condensers, and air-cooled frequency converter, etc. into DCS. In addition, a flowmeter can be fixed on the working medium circulating pipeline and hot water pipeline, and thermometers on the outlet pipeline of evaporators and preheaters can be changed to long distance temperature instrument for future operational optimization.

\subsubsection{Improper Selection of Working Medium Circulating Pump}

Sliding vane pumps were selected during the preliminary design for the working medium circulating pumps, which utilized a frequency converter to control the rotative speed difference as well as used series connection between two pumps for operation. Therefore, pump outlets bore great pressure fluctuation, pipes had large vibration, and liquid level control for evaporators was unstable, leading to serious impact on the system's long-term running. During the secondary stage of major changes, sliding vane pumps were changed to screw pumps and series connection was changed to parallel connection. Consequently, pump vibration and unstable working medium flow were solved, and the system operation was steadily. 


\subsubsection{Influence of Ambient Temperature on Generator Load}

Under a certain hot water flow and temperature, the key factors to determine the system's net generation are evaporator pressure, working medium flow, condensing pressure and temperature of working medium after working in the screw expander, as well as opening of the air-cooled frequency converter. It was pointed out during the design stage of the ORC generator sets that its electricity production in winter is higher than in summer. This is mainly because the condensing temperature of the system changes with the ambient temperature under the same hot water temperature and flow, as well as evaporating temperature and pressure. This then brings about changes of discharge pressure and system pressure difference as well as the system's electricity production and generating capacity of hot water per ton, and the system's operating efficiency. Figure 6 shows the variation trend of ambient temperature and electricity production of hot water per ton over time. The underlying cause for this problem is the use of evaporative wet air cooler as condenser.
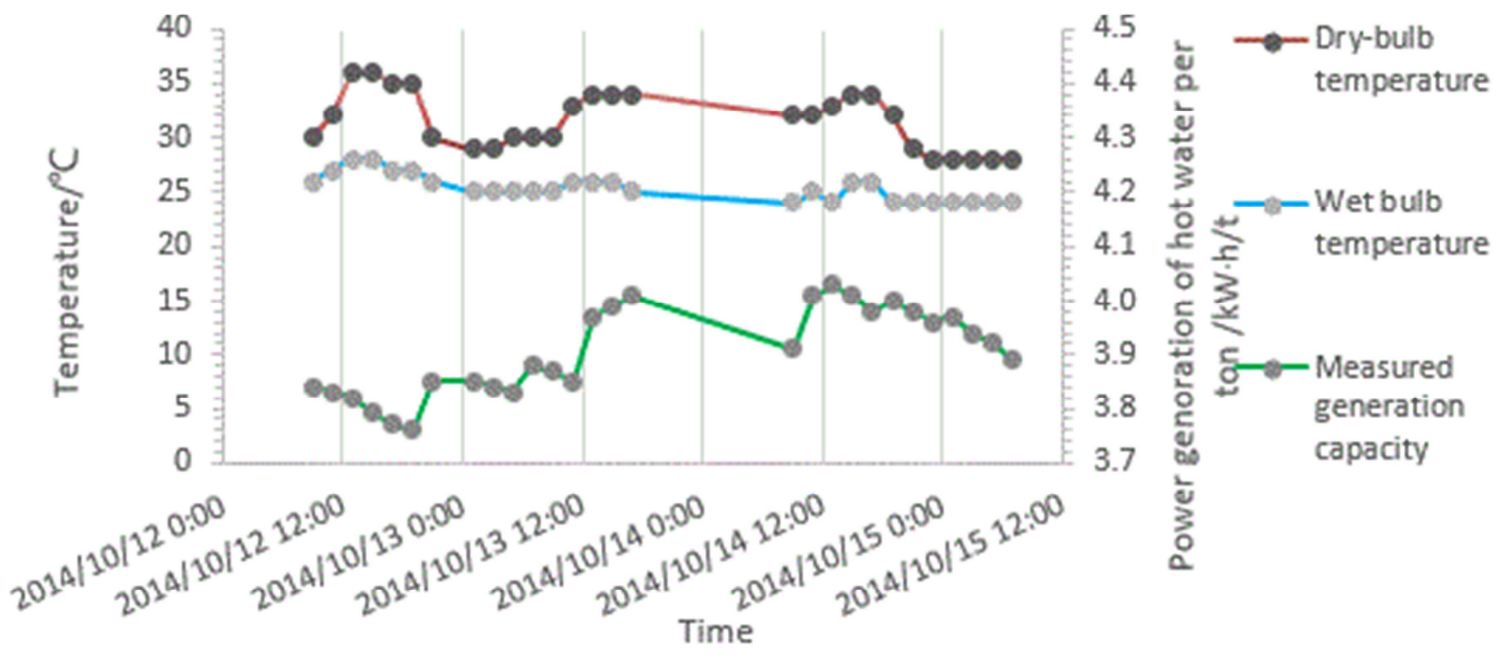

Figure 6. Changes in ambient temperatureand tons of water power genoration vs time.

\subsubsection{Decrease of Cooling Efficiency and Increase of Discharge Pressure}

Fresh water is used by evaporative wet air coolers for spray cooling and makes for fast scale depositing speed, which further affected the cooling effect of steam exhaust after working in the screw expander turbine. Hence, the cooling temperature and the exhaust pressure are gradually increased, and the overall generating efficiency of the unit is reduced. Under the operating condition of $205.4 \mathrm{t} / \mathrm{h}$ (hot water production) and $120.2^{\circ} \mathrm{C}$ (temperature), the calibration data and actual operation data of KE710 and KE630 after $72 \mathrm{~h}$ are shown in Table 2.

Table 2. Calibration data and operation data of KE710 and KE630.

\begin{tabular}{|c|c|c|c|c|c|c|}
\hline \multirow{2}{*}{ Item } & \multicolumn{3}{|l|}{ KE710 set } & \multicolumn{3}{|l|}{ KE630 set } \\
\hline & runtime value & calibration value & Difference value & runtime value & calibration value & Difference value \\
\hline Ambient temperature $/{ }^{\circ} \mathrm{C}$ & 30.5 & 31.5 & -1 & 30.5 & 31.5 & -1 \\
\hline Cooled temperature $/{ }^{\circ} \mathrm{C}$ & 39.5 & 36.6 & 2.9 & 40.7 & 36.0 & 4.7 \\
\hline Waste temperature $/{ }^{\circ} \mathrm{C}$ & 58.8 & 56.9 & 1.9 & 49.1 & 53.7 & 4.6 \\
\hline Ambient temperature difference $/{ }^{\circ} \mathrm{C}$ & 9.0 & 5.1 & 4.5 & 10.2 & 4.5 & 5.7 \\
\hline Cooled temperature difference $/{ }^{\circ} \mathrm{C}$ & 19.3 & 20.3 & 1 & 8.4 & 17.7 & 9.3 \\
\hline
\end{tabular}

It is discovered in Table 2 that the temperature and exhaust pressure after cooling of the two sets were higher than their calibration data and their pressure differences were reduced with decreased generating efficiency. However, KE630 cooled faster; its average temperature difference after cooling $\left(8.4^{\circ} \mathrm{C}\right)$ under the current condition reduced $9.3^{\circ} \mathrm{C}$ compared to the temperature difference under calibration condition $\left(17.7^{\circ} \mathrm{C}\right)$, and tended to further decline mainly because of blade erosion of wet air coolers and scaling of heat exchangers.

\subsection{Problems of Hot Water Power Generation Equipment and Solutions}

\subsubsection{Maintainability not Considered During Design and Installation}

The entire ORC system was compactly installed, which 
saved space but failed to consider maintainability. The operating space between equipment and between equipment and pipelines is not big enough for relevant personnel to implement maintenance. During overhaul, it is necessary to disassemble the equipment; however, screw expanders and generators are heavy, and lifting operation by hand-pulled hoists is time-consuming and laborious. In the design of new sets, it is recommended that a shared patrol and inspection channel of $0.5-1 \mathrm{~m}$ wide for both the system and evaporators can be reserved, sufficient space be left for maintenance at the outlet flanges of the sets, and electric hoists be installed on the two-layer steel structure.

\subsubsection{Manufacturing Malfunction of KE710 Generator}

After the operation test of the system upon completion, the vibration velocity in operation at the non-driving end of the generator was too high. Despite a series of rectification measures, the fundamental problem still remained, leading to be badly damaged of the generator which was then returned to the factory for repair. Corresponding components were replaced and the generator's vibration velocity became normal; however, there were still problems, such as large electromagnetic noise, and a large number of high frequency current spectrum signals in the acceleration spectrum.

\subsubsection{Large Vibration of KE710 Screw Expander Unit}

The research and development of screw expanders in domestic manufacturers are in its infancy at the moment. Research suggests that the suction side pressure of expanders is much higher than that of the exhaust side, and the maximum deformation position of the rotor appears at the tooth top of the suction side. Accordingly, rotor deformation should be reduced during the design of rotor lines to avoid wear and breakage. By spectrum analysis, the vibration velocity spectrum of KE710 at vertical measurement points mainly reflected the mesh frequency of male and female rotors and their harmonic waves. Large vibration was possibly caused by bad meshing of the two rotors, airflow induce, poor foundation stiffness, and low accuracy of rotor dynamic balance. The reason for vibration is related to the design, manufacture, assembly and pipeline layout of the expander. During the major overhaul period, the original screw expander was replaced with the latest and optimized screw expander designed by Kaishan Group. The vibration value of the new set after two months of full-load operation was stably above $3.5 \mathrm{~mm} / \mathrm{s}$, meeting the requirement of long-term steady operation [10-12].

\subsubsection{Loud Operation Noise}

Similar to screw compressors with electric motor, screw expander generator set mainly has three kinds of noise sources: gas pulsation, mechanical noise and electromagnetic noise. These noise sources can be effectively controlled by improving mechanical design, machining precision and assembly quality of expanders and generator parts, as well as by reforming the process and operation method [13].

Considering actual practices of the factory, passive noise control measures can be taken in the case that active noise reduction process is not ideal, namely, strengthening employees' self-protection awareness, and taking active individual protection measures. Wearing protective earmuffs during inspection operations according to requirements can effectively abate the damage of noise on the hearing system.

\subsubsection{Problems in Condenser Selection and Frequency Converter Setting}

Due to evaporative wet air cooling of condensers, cooling air fans and water pumps are the main power consumption devices in the system and the power consumption of the system increased $101 \mathrm{~kW} \cdot \mathrm{h}$. The condenser fan has a single frequency setting in operation and generally runs at full capacity in summer, but the power consumption of the system increases; in winter, the frequency converter can save $8 \sim 10$ $\mathrm{kW} \cdot \mathrm{h}$. There is a short period of low temperature in winter in Hainan while a long term of high temperature in summer; therefore, energy-saving effect of frequency converters is not significant, the investment costs are increased and the unit is not stable in operation. By-pass controls are suggested to be installed on the fan frequency converters, and power frequency mode should be used in summer. In addition, the wet air cooler does not have dedicated cleaning pipes, and is thus difficult to clean after scaling. In allusion to this problem, a pressurizer should be added to the pipeline based on the current spraying system to carry out high-pressure cleaning, guaranteeing its cooling effect. The wet air can easily accelerate the corrosion of guardrails, fan blades and pipes of the air-cooled platform, and the water tank of the wet air cooler needs to be regularly cleaned, causing high maintenance costs during the whole using life [14].

\subsubsection{Leakage of Seal Rings in the Working Medium Circulation}

Although R245fa has low toxicity, it still has potential hazards to the human body and the environment. The Occupational Safety and Health Administration regulates that the maximum allowable concentration of TWA is 300ppm, The flange joint face of the ORC inlet and outlet pipelines has static seal leakage. The driving end of the screw expander adopts John Crane multiple-spring mechanical seal, and has potential sealing leak in operation due to large vibration of the set. The compensation mechanism of the mechanical seal mainly includes spring and bellow types. Compared to spring mechanical seal, bellow type has better floatability along the axial and inclined directions, and can significantly improve sealing ability and low down requirements on installation technology. During the next transformation, it is recommended to use complete spring type or bellow type mechanical seal to improve its mobility, reliability and service life, as well as to replace the rubber gasket at the static sealing leak to reduce working medium consumption and impact on environment [15].

\section{Operational Condition of ORC Generator Sets}

The ORC generator sets were combined to the grid for 
power on May 20, 2014. Under 100\% working load from October 12 to 15,2014 , the author calibrated the ORC system for $72 \mathrm{~h}$ and obtained its main operational data shown in Table 3. The table shows that its operating load was lower than its calibration load under the same heat sources. There are two main causes: 1. After running for a period of time, the heat exchanger and condenser started to form scale and thus had lower heat exchange efficiency under the same heat source, leading to decrease of evaporating pressure and temperature and increase of discharge pressure and temperature; therefore, the system's power production efficiency was reduced. 2. Expander started to wear and had greater internal leakage, giving rise to low efficiency.

Table 3. Design value, calibration value and actual value of the system.

\begin{tabular}{|c|c|c|c|}
\hline Item & Design Value & calibration value & Actual value \\
\hline Dry-bulb temperature $/{ }^{\circ} \mathrm{C}$ & $4.3 \sim 40$ & 32 & 31 \\
\hline Water inlet temperature $/{ }^{\circ} \mathrm{C}$ & $118 \sim 123$ & 119 & 122 \\
\hline Water outlet temperature $/{ }^{\circ} \mathrm{C}$ & 70 & 72 & 75 \\
\hline Hot water flow $/\left(\mathrm{t} \cdot \mathrm{h}^{-1}\right)$ & $190 \sim 205$ & 204 & 205 \\
\hline KE710 net generation/(kW $\bullet h)$ & 710 & 457 & 426 \\
\hline KE630 net generation $/(\mathrm{kW} \cdot \mathrm{h})$ & 630 & 339 & 326 \\
\hline Total net generation/(kW・h) & 926 & 796 & 751 \\
\hline Hot water temperature difference $/{ }^{\circ} \mathrm{C}$ & 48 & 47 & 46 \\
\hline Net generation of water per ton $/(\mathrm{kW} \cdot \mathrm{h})$ & 4.63 & 3.91 & 3.66 \\
\hline
\end{tabular}

\section{Conclusion}

1. Design of the ORC generator sets should be carried out based on site conditions, and should consider space for personnel patrol and inspection as well as maintenance to ensure its maintainability. Vibration, noise and leakage of the unit should meet relevant standards by optimizing its design and selection of seal rings as well as improving expanders' and generators' assembly precision. Optimum condensers should be chosen based on the environmental conditions in Southern areas to improve the system's overall economic benefits.

2. Considering the cascade control for hot water utilization and bypass valve design on the main hot water pipeline in the ORC generator sets, it is necessary to make sure that the secondary unit is able to make full use of heat sources and remain high generation efficiency when the primary unit breaks down and runs at a low load to improve the overall operational efficiency of the system. When new technology and equipment are introduced, it is essential to obtain corresponding control authority and optimize the control module to avoid a closed loop control which is not conducive to the operation, maintenance, and centralized control of equipment.

\section{References}

[1] Chi Shenggang. "Assessment of commercial operration of first ORC power generation train in petrochemical industry", J. Petroleum Refinery Engineering, 2017, V, 47, №2, pp. 60-64.

[2] Wang Hua, Wang Huitao. "Organic Rankine cycle technology for low temperature waste heat generation", M. Beijing, Science press, 2010 (in Chinese).

[3] Matsuda K. "Low heat power generation system" [J]. Applied Thermal Engineering, 2014, V, 70, №2, pp. 1056-1061.

[4] Qin Wenge. "The application of low-temperature heat recovery technology in Aromatic complex unit", D, South China University of Technology, 2014. (in Chinese).
[5] Wei Lil, Zhang, Yufen, Mu, Yongcha."Study of evaporator in low-temperature energy conversion system using organic rankine cycle” CRYOGENICS, 2015, V, 208, №6, pp. 31-36.

[6] Cao Binbin, Li Weiyi."Analysis of Dual-Cycle Low-Temperature Waste Heat Recovery System with Screw Expander”, Journal of Tianjin University, 2010, V, 43, №4, pp. 310-314.

[7] $\mathrm{Wu}$ Huagen, Tang Hao, Chen Wenqing, Xing Ziwen. "Research and development of Steam twin screw expander," J. Journal of Xi'an Jiaotong University, 2014, V, 48, №3, pp. 1-5.

[8] YANG Xin-le, HUANG Feifei, DAI etc. "Analysis of the Thermal Performance of a New Type Stepped Heat Exchange Organic Rankine Cycle System.” Journal of Engineering for Thermal Energy \& Power, 2016, V, 31, №S5, pp. 16-21.

[9] WANG Hui, MA Xinling, MENG Xiangrui. "Effect of mass flow rate on performance of organic Rankine cycle for power generation system with low-temperature waste heat" CIESC Journal, 2015, V, 66, №10, pp. 4185-4192.

[10] Liu Guangbin, Zhao Yuanyang, Yang Qichao."Study on characteristics of screw expander's rotor profile", J. Refrigeration And Air-conditioning, 2014, V, 14, №6, pp. 25-27.

[11] Chi Shenggang. "Vibration reason analysis and treatment methods for the first ORC generation set in petrochemical industry," J. Petroleum Refinery Engineering, 2017, V, 47, №11, pp. 43-47.

[12] Donald E. Bently, Charles T. Hatch. "Fundamentals of Rotating Machinery Diagnostics," M. China Machine Press, 2014 (in Chinese).

[13] Cheng Shuangling, Li Guoliang, Zhang Qiuju. "Study of the noise control of screw compressor. "Fluid machinery, 2007, V, 35, №2, pp. 43-45.

[14] DONG Bing*, ZHANG Kai, GAO Lei, XING Zi-wen. "Performance Analysis of ORC Screw Expansion Power Generation Set in Different Regions and Seasons," J. Chinese Journal of Refrigeration Technology, 2015, V, 35, №1, pp. 11-16.

[15] DUAN Zhi-qiang, Liu Ming-zhi, FU Lin-jia. "The research of the reconstruction from spring mechanical seal into bellows mechanical seal,” J. Machinery, 2005, V, 32, №1, pp. 6-9. 